\title{
Paediatrics in Vienna
}

\author{
Fabio Midulla', Enrico Lombardi², Karin C. Lødrup Carlsen ${ }^{3}$, Nicolas Regamey $^{4}$, \\ Jonathan Grigg ${ }^{5}$, Robert I. Ross Russell ${ }^{6}$, Steve W. Turner ${ }^{7}$, Kostas Priftis ${ }^{8}$ and \\ Ernst Eber ${ }^{9}$
}

\section{Affiliations:}

${ }^{1}$ Dept of Paediatrics, Sapienza University of Rome, Rome, and

${ }^{2}$ Dept of Paediatrics, Anna Meyer Paediatric University Hospital, Florence, Italy.

${ }^{3}$ Dept of Paediatrics, Oslo University Hospital and the Faculty of Medicine, University of Oslo, Norway.

4Division of Paediatric Respiratory Medicine, Dept of Paediatrics, University Hospital and Inselspital, Bern, Switzerland.

${ }^{5}$ Centre for Paediatrics, Blizard Institute, Queen Mary University of London, London,

${ }^{6}$ Dept of Paediatrics, Addenbrooke's Hospital, Cambridge, and

${ }^{7}$ Dept of Child Health, University of Aberdeen, Aberdeen, UK.

${ }^{8}$ Dept of Paediatrics, "Attikon" Hospital, University of Athens, School of Medicine, Athens, Greece.

${ }^{9}$ Respiratory and Allergic Disease Division, Dept of Paediatrics, Medical University of Graz, Graz, Austria.

\section{Correspondence:}

E. Eber, Klinische Abteilung für Pulmonologie und Allergologie, Univ.-Klinik für Kinder- und Jugendheilkunde, Medizinische Universität Graz, Auenbruggerplatz 34/2, 8036 Graz, Austria.

E-mail: ernst.eberamedunigraz.at

ABSTRACT The aim of this update is to describe, in the context of the current literature, major papers from the seven groups of the Paediatric Assembly (Respiratory Physiology; Asthma and Allergy; Cystic Fibrosis; Respiratory Infection and Immunology; Neonatology and Paediatric Intensive Care; Respiratory Epidemiology; and Bronchology) presented during the annual European Respiratory Society congress held in 2012 in Vienna, Austria.

@ERSpublications

Update on major papers from the seven groups of the Paediatric Assembly presented at the ERS congress in $2012 \mathrm{http}: / /$ ow.ly/nuVqm

Received: Feb 282013 | Accepted: March 072013 | First published online: May 032013

Conflict of interest: Disclosures can be found alongside the online version of this article at www.erj.ersjournals.com Copyright @ERS 2013 


\section{Introduction}

During the 2012 annual congress of the European Respiratory Society (ERS) in Vienna, Austria, members of the Paediatric Assembly presented numerous high-quality scientific communications. As for the Scientific Assembly Update from the 2011 annual congress [1], the chairs of the scientific groups of the Paediatric Assembly have selected and discussed the most important abstracts from each group, to give colleagues who were unable to attend the congress or a specific session a review of the research presented during the meeting. Due to the large number of contributions to the congress this summary cannot be comprehensive, but rather aims to address schemes of new research in major areas of paediatric respiratory medicine.

\section{Paediatric respiratory physiology \\ Forced oscillation}

Several studies in recent years have investigated how the various lung function techniques can be applied in clinical practice in young children. The ERS conference in Vienna reflected this tendency. For example, Albloushi et al. [2] studied the feasibility and safety of mannitol challenge using the forced oscillation technique (FOT) in 16 preschool children (aged 3-7 years). Only two children aged 3-years were unable to do the test, giving a feasibility of $87 \%$. No adverse events were reported, leading the investigators to conclude that the mannitol challenge test using FOT is feasible and safe in preschool children. In another study using the FOT, IOAN et al. [3] assessed the bronchodilator response (BDR) to a single pressure oscillation at $8 \mathrm{~Hz}$ in 79 asthmatics and 20 controls aged 4-11 years. The BDR test showed a higher Youden index (a combination of sensitivity and specificity in discriminating asthmatics from controls) during inspiration than during expiration for several FOT indices, suggesting that the inspiratory BDR may help in diagnosing asthma in children. Similarly, RADICS et al. [4] assessed within-breath changes in respiratory impedance in 37 healthy newborns during natural sleep using forced oscillations at $16 \mathrm{~Hz}$ with the wave tube technique [5]. They found that respiratory resistance depended more on flow than on volume, showing flow nonlinearities in the narrow airways. The wave tube technique is an exceedingly promising tool for measuring lung function in unsedated infants. In a later study, HANTOS et al. [6] reported $88 \%$ feasibility in healthy 1-day-old newborns.

\section{Multiple breath washout}

Several studies addressed the multiple breath washout (MBW) technique, most were designed to evaluate its potential applications in clinical practice. RATJEN et al. [7] used the reference standard sulfur hexafluoride mass spectrometer-based MBW system to validate a recently released nitrogen washout ultrasonic flow meter-based commercial system in 24 healthy children and 33 children with cystic fibrosis (CF). They found that the lung clearance index (LCI) was systematically 0.2 units (95\% CI $0.06-0.33$ ) lower with sulfur hexafluoride than with nitrogen washout, confirming that the values obtained with the two techniques cannot be used interchangeably. Interestingly, the mean LCI difference was greater in children with CF (0.4 units, 95\% CI 0.29-0.55). Using a different nitrogen washout ultrasonic flow meter-based commercial system, FuCHs et al. [8] differentiated 11 patients with CF (aged 7-25 years) from 19 healthy controls (aged $7-51$ years). The mean \pm SD LCI was $6.5 \pm 0.64$ units in controls and $9.3 \pm 1.93$ units in CF with a mean difference of $-2.83(95 \%$ CI $-4.14--1.51 ; \mathrm{p}<0.001)$ between the groups. Within-test repeatability (coefficient of variation \%) was $5.3 \%$ in controls and $7.7 \%$ in CF. These results support the conclusion that MBW of nitrogen can differentiate patients with CF from controls, as previously published data have shown for MBW of sulfur hexafluoride [9]. In a clinical and imaging study, HATZIAGOROU et al. [10] used MBW and low-dose chest computed tomography (CT) in 14 subjects with non-CF bronchiectasis and normal forced expiratory volume in $1 \mathrm{~s}$ (FEV1). They found that LCI had $87 \%$ sensitivity and 50\% specificity in detecting structural lung damage as shown by CT scans. These results suggest that LCI may be a suitable surrogate marker for monitoring progression of lung disease among children with non-CF bronchiectasis. The same group compared LCI and exercise capacity in 15 children with stable CF (mean age 13.7 years), 14 children with stable non-CF bronchiectasis (mean age 13.8 years) and 15 healthy children (mean age 13.6 years) [11]. While the mean LCI was significantly higher among patients with CF and those with non-CF bronchiectasis (13.7 and 11.8 units, respectively) than in healthy children $(\mathrm{p}<0.001)$, no significant difference was found between children with CF and non-CF bronchiectasis $(p=0.16)$. Similar results were found for exercise capacity: no significant difference was found between the mean peak aerobic capacity in children with $\mathrm{CF}$ and those with non-CF bronchiectasis $(62.2 \%$ predicted versus $77.3 \%$ pred $)(\mathrm{p}=0.06)$, whereas both groups differed significantly from controls $(\mathrm{p}<0.001)$. In a similar study, GREEN et al. [12] compared MBW in 24 children with primary ciliary dyskinesia (PCD) (mean age 13.0 years) and 25 children with CF (mean age 12.3 years). They found that LCI and ventilation inhomogeneity indices in the conductive and acinar airway zones were abnormal, but not significantly different, in the two groups. These results suggest that, in contrast to the lower morbidity usually seen in children with PCD than in those with CF, the severity of peripheral airway involvement is similar in children with these diseases. 


\section{Reference values}

Proper reference values are essential for interpreting lung function measurements [13]. As part of the Global Lungs Initiative (GLI) (www.lungfunction.org) and an ERS Task Force, STOCKS et al. [14] reported global reference equations for spirometry from 74187 healthy nonsmokers aged from three to 95 years. Reference equations for Caucasians, African Americans, south-east Asians and north-east Asians were produced using modern statistical methods and assessing age-dependent lower limits of normality. For individuals not represented by these four groups a composite equation was provided. The GLI reference equations 2012 for spirometry are a major step forward [15] and their widespread use will depend on timely implementation by manufacturers of spirometric devices. Studying another possible reference tool, ULRICH et al. [16] reported reference equations for the 6-min walk test (6MWT), a simple and reliable tool [17] to assess exercise capacity in various chronic diseases, collected from 496 healthy children aged 5-17 years. In regression models age was the best single predictor of walking distance in younger age children, whereas anthropometrics were more important in girls and adolescents. Exercise heart rate was also an important distance predictor, in addition to age, and in most subgroups assessed outreached anthropometrics.

\section{Follow-up of children born very prematurely}

This is a major clinical issue, insofar as prematurity may result in long-term respiratory morbidity [18]. To address a specific problem related to prematurity, ORUC et al. [19] studied respiratory impedance using impulse oscillometry in 86 preschool children (aged 3-6 years) who were born with a very-low birth weight $(<1500 \mathrm{~g})$ and 40 term-born age-matched controls. Respiratory impedance testing disclosed bronchopulmonary dysplasia (BPD) in $43 \%$ of the preterm children. Although respiratory resistance was significantly higher and reactance was significantly lower in preterm children than in controls, these indices were not significantly different in preterm children without BPD and those with BPD, suggesting that lung function is impaired in preschool children born very prematurely even without a history of chronic lung disease. Addressing a similar problem, ZIVANOviC et al. [20] assessed spirometry at 12-13 years in children born very prematurely (23-28 weeks of gestational age) from the UK Oscillation Study. They found that more males than females had reduced FEV1 $(22 \%$ versus $3.5 \%$; $\mathrm{p}=0.036)$, higher residual volume $(34 \%$ versus $4 \% ; \mathrm{p}=0.009)$ and higher functional residual capacity $(26 \%$ versus $0 \% ; \mathrm{p}=0.008)$, but these differences were not explained by greater airway hyperreactivity to cold air challenge $(24 \%$ versus $26 \%$; $=0.94)$.

\section{Physiological monitoring during sleep and in neuromuscular disease}

The evaluation of respiratory physiology in children with sleep disordered breathing or neuromuscular disease is also a very important topic for clinical practice. When studying the polysomnography data of 33 nonobese children aged 0.2-8 years, WONG et al. [21] found that children with trisomy 21 and pulmonary arterial hypertension $(\mathrm{PAH})(\mathrm{n}=6)$ had a significantly higher obstructive apnoea/hypopnoea index than those with PAH alone $(n=9)$ or trisomy 21 without PAH $(n=10)$ or children with neither trisomy 21 nor PAH $(n=8)(p=0.01)$. These results suggest that children with both trisomy 21 and PAH are at increased risk of having obstructive sleep apnoea and should undergo sleep surveillance with polysomnography. Seeking more information on sleep disordered breathing, LOMAURO et al. [22] used optoelectronic plethysmography to study cough in 36 subjects with Duchenne muscular dystrophy (DMD) and 15 healthy controls during quiet breathing and maximal cough. The subjects' mean age was 16.3 years. In 15 children with DMD with inefficient cough (peak cough flow $<160 \mathrm{~L} \cdot \mathrm{min}^{-1}$ ), thoracoabdominal asynchrony during cough (laboured breathing index) was higher and percentage abdominal contribution to tidal volume was lower than in controls or in those with efficient cough $\left(n=9\right.$, peak cough flow $\left.>270 \mathrm{~L} \cdot \mathrm{min}^{-1}\right)$. These data suggest that percentage abdominal contribution to tidal volume, a technique that does not require active collaboration, may be a useful tool for predicting inefficient cough in children with DMD.

\section{Paediatric asthma and allergy}

\section{Severe asthma}

Severe childhood asthma has, over recent years, received long overdue attention. First, through a series of review papers in the European Respiratory Journal, uniting scientists and clinicians throughout Europe via the Global Allergy and Asthma European Network (GA ${ }^{2}$ LEN) initiative (defining, assessing and managing severe childhood asthma) [23-25], with further updates discussing management issues [26, 27] and lessons learned from large collaborative programmes collating information on severe asthma in children and adults $[28,29]$. UlLmann et al. [30] described the underlying inflammation and structural changes in severe asthma demonstrating increased submucosal interleukin-33 expression is associated with airway remodelling in children with severe therapy-resistant asthma. HeIDA et al. [31] demonstrated the usefulness of bronchoscopy in children with severe asthma, leading to treatment changes in $25 \%$ of the patients, but found no significant difference in reticular basement membrane thickness between non-asthmatic children, asthmatic children and children with difficult asthma. KONRADSEN et al. [32] reported that children with 
high levels of per cent exhaled nitric oxide fraction had increased morbidity that was partly independent of predefined severity classification. These results follow a recently published paper demonstrating eosinophilic inflammation in the absence of T-helper cell type 2 inflammation in paediatric severe asthma [33]. In a collaborative study between the UK and Poland, IвRAнiм et al. [34] did not find increased urinary eicosanoid levels in preschool children with multitrigger wheezing when compared with episodic wheezing.

\section{Allergy}

The development of allergy is a hot topic in paediatrics, and the role of natural tolerance development related to microbial diversity in early life in protecting against allergic inflammation development is increasingly acknowledged [35-37]. CHAUVEAU et al. [38] showed that skin reactivity increased with age and was lower in children exposed to a farm environment. MiCHel et al. [39] reported that DNA methylation in specific asthma and allergy-related genes changed significantly in early childhood, suggesting that early exposure to farming might influence methylation patterns in certain genes. A group from Leicester, UK followed up the long-debated question of breastfeeding in atopy prevention, reporting no evidence for an effect of breast-feeding on atopy in children of mothers either with or without hay fever when controlling for reverse causation [40]. Equally importantly, NATHAN et al. [41] suggested, from a mouse-model study, that maternal genetic asthma predisposition may affect pulmonary microRNAs during an early developmental stage and possibly influence lung development. This parental influence may be in line with a recent observation from the Isle of White study demonstrating that paternal asthma appears to be the most important factor influencing asthma development in boys, a similar maternal line of inheritance emerged in girls up to 18 years of age [42].

\section{Asthma therapy}

Asthma treatment raises many management problems, including side-effects and assessing treatment responses, as well as preventing asthma exacerbations. In asthmatic children up to 18 years of age, ZHANG et al. [43] found that the use of inhaled beclomethasone was associated with increased risk of colonisation with certain bacteria, including Streptococcus pneumoniae, raising concern about a potential treatment-related risk of pneumonia. This is interesting in relation to the increasing evidence for finding bacteria in the airways [44] and lungs as part of a lung microbiome discussed in recent papers [45, 46]. BRINKMANN et al. [47] reported chronic bacterial infections in a subgroup of preschool children with persistent wheezing and that these children benefited significantly from antibiotic therapy. The role of viral infections [48], as well as a potential role of bacterial infection $[49,50]$, in asthma is likely to prompt many studies in the future. Regular use of inhaled corticosteroids during childhood may be related to a decrease in bone mineral density, although the clinical effect of these findings may be evident only later in life, as shown by Sidoroff et al. [51]. In addition, ZOELLNER et al. [52] reported that approximately two-thirds of 143 asthmatic children (5-18 years of age) on glucocorticosteroid therapy may have a degree of hypothalamic-pituitary-adrenal axis suppression and that in some the adrenals may still be suppressed whereas hypothalamic-pituitary function may have recovered. The response to intramuscular triamcinolone, used to assess steroid response, was shown to vary by ethnicity, highlighting the urgent need to standardise such tests in managing difficult asthma, as demonstrated by KoO et al. [53]. The role of magnesium sulfate (inhaled or i.v.) in acute childhood asthma remains controversial. SHEIKH et al. [54] showed that of 222 children aged $>5$ years admitted to paediatric intensive care, the 57 who had received magnesium sulfate had no better outcomes than those who had not; outcome was measured as length of intensive care unit (ICU) stay, need for mechanical ventilation or radiographically detected pathology. Despite wide discussion of the role of hypertonic saline as a bronchodilator, especially in relation to acute bronchiolitis, no consensus exists on how to treat acute airway obstruction associated with respiratory viruses, regardless of whether it is due to bronchiolitis, "wheezy lower respiratory tract infection" or asthma. ATER et al. [55] reported, in 41 preschool children (1-6 years of age, mean age 32 months), that compared with saline, the use of hypertonic saline was associated with a shorter hospital stay as well as a lower hospital admission rate. Because the study failed to compare hypertonic saline with a $\beta 2$-agonist, its potential efficacy over $\beta 2$-agonists remains unclear. New treatment modalities are urgently needed for severe asthma. In a mouse model, MAYs et al. [56] showed that a chemically modified forkhead box P3 mRNA delivered intrathecally protected against allergic asthma in vivo, possibly paving the way for considering modified mRNA in the treatment of asthma and allergy.

\section{Cystic fibrosis}

\section{Clinical studies}

In many countries, $\mathrm{CF}$ is now detected by newborn screening. One of the difficulties in newborn screening programmes is confirming CF diagnosis by sweat testing, because in young infants sweat can be collected only in small amounts. Seeking a better method for sweat testing, BARBEN et al. [57] presented pilot data on 84 children who were screened positive for CF and referred for sweat testing. They showed that the Nanoduct 
system (Wescor, Inc., Logan, UT, USA), which measures conductivity and needs only a few microlitres of sweat, yields a higher proportion of reliable tests than the Macroduct (Wescor, Inc.) collection system (79\% versus $66 \%$, respectively), which needs higher sweat volumes for chloride concentration measurement.

Inflammation, infection and small airways disease appear early in life in CF $[58,59]$. Respiratory virus infections could be important in triggering the inflammatory cascade early in life and damaging the CF airways. In a prospective longitudinal multicentre pilot study, POREDDY et al. [60] analysed nasal swabs for respiratory viruses collected every fortnight in 78 children with CF under the age of 3 years. During periods of respiratory symptoms, a larger percentage of swabs were positive for viruses when compared with asymptomatic children (45\% versus 19\%, respectively), a difference similar to that reported in children without underlying lung conditions, suggesting that children with $\mathrm{CF}$ are not infected by respiratory viruses more often than healthy infants, but that they suffer worse clinical consequences.

Interesting observations were reported in young children with CF. POREDDY et al. [61] reported a high prevalence of tracheobronchomalacia (14\%) whose significance remains unknown. METE et al. [62] showed that children with CF seem to have good dental health, possibly related to good oral hygiene and to a high buffering capacity of saliva.

In adolescence, genotype, CF-related diabetes mellitus and Pseudomonas aeruginosa infection are all associated with an increased rate of decline in lung function, as highlighted by WELSH et al. [63] in a retrospective review of data from the Royal Children's Hospital, Melbourne, Australia. However, additional factors are likely to contribute to lung function decline in adult patients with CF and smoking in CF patients is a real threat. Investigating smoking habits in patients with CF, GoDDING et al. [64] reported that $\sim 5 \%$ of Belgian patients with CF were active smokers.

Tools that measure health-related quality of life (HRQoL) are important instruments to assess disease progression and monitor therapeutic interventions, especially in adult CF patients. TEPPER et al. [65] showed that HRQoL assessed by the CF questionnaire-revised (CFQ-R) correlates well with the extent of bronchiectasis and trapped air on chest CT. In a similar study, CEBRIAN et al. [66] compared three questionnaires (CFQ-R, St George's Respiratory Questionnaire (SGRQ), and the Short-Form-36-item (SF-36) health survey) in 75 adolescents and adults with CF and concluded that the CFQ-R is the most suitable to measure HRQoL. Conversely, Hofer et al. [67] showed, in 32 adult CF patients, that the SGRQ correlates better with pulmonary function than the CFQ-R.

Finally, investigating end-stage lung disease related to CF, AVDEEV et al. [68] showed that survival is improved in patients receiving home noninvasive positive-pressure ventilation than in patients treated with long-term oxygen therapy alone.

\section{Lung function}

Conventional lung function techniques, such as spirometry, are too insensitive to detect early small airway dysfunction in CF and the correlation between spirometry indices and structural lung damage is poor [69]. Inert tracer gas washout tests, which provide a more sensitive alternative in detecting and tracking small airway dysfunction and better reflect structural changes in the lung periphery, have emerged as promising tools to monitor early CF lung disease and progression [70]. Until recently, these tests were done mainly in a research setting, because they relied on custom made setups, e.g. mass spectrometers. The more advanced commercially available instruments using the nitrogen MBW technology and new MBW guidelines may help translate MBW research into clinical practice [71]. However, caveats exist, especially when adult protocols are adapted to children. For instance, YAmmine et al. [72] showed that a $1 \mathrm{~L}$ tidal volume breathing protocol, which is widely used in adults, impacts on nitrogen MBW indices in school-aged children.

If MBW is to enter routine clinical practice, research urgently needs to provide normative values for indices derived from MBW. Seeking to fill this gap, LuM et al. [73] recently published normative data for the mass spectrometer system and the inert gas sulphur-hexafluoride in 497 healthy subjects aged 2 weeks to 19 years, and Houltz et al. [74] provided values for nitrogen MBW in 284 subjects aged 7-70 years. As pointed out by SINGER et al. [75], future research needs to investigate whether and, if so, to what extent the LCI, especially in the infant lung volume range, depends on computer hardware and software.

The LCI is the most commonly used outcome measure of inert tracer gas washout. AL-KHATHLAN et al. [76] showed that the LCI correlates with indices of hyperinflation obtained by plethysmography in CF children. These data are in line with previous findings in adult CF patients suggesting that the LCI depends on airway dead-space [77]. Using data from a previous randomised controlled trial that had detected a treatment response from hypertonic saline inhalation in patients with mild CF lung disease [78], RATJEN et al. [79] investigated whether any other outcomes of the MBW could detect treatment effects similar to LCI. Their results suggest that moment ratios, which may be less sensitive to variations in respiratory rate and tidal 
volume, may provide a complementary outcome to the LCI in clinical trials. In a cross-sectional study including 71 patients with CF, AL JASSIM et al. [80] found that the phase III slope index estimating ventilation inhomogeneity arising in the conductive airway zones provided an early marker of lung involvement.

Although nitrogen MBW can be successfully used in children with CF [81], even in preschoolers as has been shown by Zirbes et al. [82], the technique is time-consuming. Seeking to overcome this disadvantage, a Swiss group demonstrated that two alternative MBW protocols using fewer measurements (one or two runs instead of three) or LCI determined at one twentieth of the starting end-tidal nitrogen concentration are promising measures for time-saving and repeated LCI measurements in clinical routine [83, 84].

Finally, АвBAS et al. [85] tested the immediate effects from physiotherapy and inhalation on pulmonary function using a new double-tracer gas single-breath washout (SBW) during tidal breathing, which uses helium and sulfur hexafluoride as tracer gases. Their findings suggest that the tidal double-tracer gas SBW may be a suitable test to track changes in gas mixing in children with mild CF lung disease.

\section{New therapies}

Ivacaftor (Kalydeco formerly known as VX-770; Vertex Pharmaceuticals, Cambridge, MA, USA) is a CF transmembrane conductance regulator potentiator that has been shown to improve lung function, decrease pulmonary exacerbations, lead to weight gain and decrease sweat chloride concentrations in CF patients $\geqslant 12$ years with the G551D mutation [86]. ELBORN et al. [87] presented the results of the ENVISION study, a randomised, double-blind, placebo-controlled multicentre study, which enrolled 52 CF subjects with the G551D mutation who were aged 6-11 years. Ivacaftor led to a $12.5 \%$ absolute change in FEV1 \% predicted through week 24 , a change similar to that seen in older patients. Because too few subjects experienced pulmonary exacerbations, no meaningful comparison could be made with placebo. In a subgroup analysis of patients with mild lung disease (FEV1 $>90 \%)$, RATJEN et al. [88] showed that mean LCI decreased by 2.07 after treatment with ivacaftor for 4 weeks. Extending ivacaftor research, McKonE et al. [89] presented the results of the 96-week open-label extension (PERSIST) study, which evaluated the safety and efficacy of long-term ivacaftor in the subjects who completed the prior STRIVE and ENVISION trials. They showed that ivacaftor induced sustained improvements and identified no clinically important safety concerns. The drug has recently been approved in the USA and in Europe for the treatment of CF patients $\geqslant 6$ years of age who have a G551D mutation.

\section{Paediatric respiratory infection and immunology Air pollution and infection}

Air pollution is associated with increased vulnerability of children to lower respiratory tract infection [90]. Because epidemiological studies are less effective in identifying the specific components of air pollutants underlying this association, in vitro models remain important. SURI et al. [91] examined the combined effect induced by fossil-fuel derived particulate matter and cigarette smoke extract on S. pneumoniae adhesion to lower airway cells. In this model, particulate matter and cigarette smoke extract per se increased the capacity of airway epithelial cells to support pneumococcal adhesion, but when combined also induced an additive effect on bacterial adhesion. Because other pollutants may have a role in modulating vulnerability to infection, KIM et al. [92] assessed the effect of sulphur dioxide on lower airway epithelial cells. In this model, cell pretreatment with sodium sulphite before infection with rhinovirus 7 enhanced pro-inflammatory cytokine release, but had no effect on viral replication. The use of $S$. pneumoniae in models is clearly valid. In a UK national surveillance study investigating empyema in children, SPENCER et al. [93] reported that pneumococcal infection accounted for $68 \%$ of the cases (where a bacterial cause was found), followed by Streptococcus pyogenes (14\%) and Staphylococcus aureus (4\%). Another appropriate infectious agent is rhinovirus. Studies investigating how air pollution influences infection should nevertheless take into account the newly identified rhinovirus group C, given that Cox et al. [94] reported that this is the most common rhinovirus infection associated with acute lower respiratory infection in children presenting to an Australian hospital. The validity of in vitro models also depends on how accurately the responses in airway epithelial cell lines reflect responses in vivo. To address this question, Wilson et al. [95] infected undifferentiated cell lines and differentiated tracheobronchial epithelial cells with nontypeable Haemophilus influenzae. Differentiated cells contained fewer bacteria than undifferentiated cells suggesting upregulated innate defensive mechanisms in the more differentiated cells.

\section{Chronic bacterial infection}

Chronic bacterial infection is a major factor driving lung inflammation and airway damage in CF and PCD. GHORBAni et al. [96] studied changes in P. aeruginosa growth induced by short-chain fatty acids (SCFA). SCFAs are produced by anaerobic fermentation, especially in more acidic environments. This study found that SCFA concentrations in CF sputum stimulated $P$. aeruginosa growth. Thus, SCFA release may be one 
mechanism by which $P$. aeruginosa protects itself from immune clearance. Another way that bacteria evade immune clearance and antibiotic killing in the airway is by producing biofilms. Hence, WALKER et al. [97] investigated the ability of $H$. influenzae isolated from the airways of PCD patients to produce biofilms. Biofilm formation by $H$. influenzae was found in all four isolates tested with increased density found in the isolates from the two patients with colonisation for $>4$ years. In a later study, WALKER et al. [98] highlighted the importance of chronic bacterial infection in PCD reporting that $H$. influenzae was the most prevalent isolate (49\% of positive cultures) in children with PCD, followed by S. aureus (19\%), S. pneumoniae (16\%), and $P$. aeruginosa $(9.5 \%)$.

\section{Bronchiolitis}

Respiratory syncytial virus (RSV) bronchiolitis is a major cause of morbidity in infants [99]. Prophylaxis with palivizumab reduces disease severity in high-risk infants, but is poorly effective. In a prospective study, enrolling over 10000 Canadian infants who received at least one palivizumab dose during the 2006-2011 RSV seasons, Mitchell et al. [100] reported a subsequent hospital admission rate of $1.6 \%$ for bronchiolitis. Most hospital admissions for RSV bronchiolitis are in infants ineligible for prophylaxis. To date, options for treating the acute disease are limited to supplemental oxygen and i.v. or nasogastric fluids. In a multicentre, randomised, double-blind controlled trial SKJERVEN et al. [101] assessed the efficacy of inhaled racemic adrenaline in 404 infants with moderate-to-severe bronchiolitis. The primary outcome was length of hospital stay. No difference was found for length of stay, neither were differences found between the active and placebo-treated groups for the secondary outcomes, i.e. need for nasogastric fluids and ventilatory support.

\section{Neonatology and paediatric intensive care \\ Neonatology}

Further evidence continues to emerge on the long-term outcome of neonatal lung disease. Several large cohorts of patients from groups in Europe, Australia and North America are providing valuable (if sometimes conflicting) data on how fetal growth affects the subsequent development of wheeze. As previously reported the relationship between airway responsiveness and asthma/wheeze is complex and probably develops outside the neonatal period [102]. Chronic lung disease and BPD remain difficult to characterise in the early years of life. SCHAAP et al. [103] have developed a score to assess quality of life that may well prove useful in evaluating progress. DARAKI et al. [104] are examining a genetic predisposition to BPD and further information should come from new evidence showing abnormal handling of reactive oxygen species in certain genetic polymorphisms. This was a small study including 42 patients, but it showed an increased risk of BPD in patients with the C/T or T/T variant. HoKUTO et al. [105] have looked at BPD development in premature mice while addressing oxygen-related injury. Their work suggests that granulocyte-colony stimulating factor can protect premature mice exposed to high oxygen concentrations against the development of BPD. New information related to neonatology is also emerging about surfactant in the delivery room. A recent Cochrane review [106] suggested that surfactant should probably only be used in preterm infants who require ventilation, for those who respond well to continuous positive airway pressure (CPAP), risk of chronic lung disease or death diminishes if surfactant is withheld. This conclusion reflects data from several recent important studies [107, 108].

\section{Paediatric intensive care}

A major area of developing interest is the respiratory care of infants and children with neuromuscular disease. Earlier in 2012, the British Thoracic Society published guidelines on respiratory care for this group of children [109] and these were discussed in a scientific symposium. The guidelines for paediatric intensive care discuss the following major areas: sleep, instituting noninvasive ventilation and the perioperative assessment of children. Their recommendations are limited by the paucity of good data, but they make numerous specific suggestions [109]. Sleep studies should be undertaken in non-ambulant children, those with a forced vital capacity below $60 \%$ predicted and children with symptoms as a screening test, but carbon dioxide tension should be measured in the more symptomatic cases. Noninvasive ventilation is an effective technique, improving both longevity and quality of life, and devices used to deliver such support are improving [110]. Separately, high-flow oxygen, as an alternative to CPAP or intubation, is becoming increasingly popular. HUFTON et al. [111] presented data on their experience in bronchiolitis. In their small study (nine patients), the benefits (reduced respiratory rate and pulse rate) were seen within 2 hours after treatment started. Techniques for assaying the specific virus causing bronchiolitis are also improving, and the results of Cox et al. [112] suggest that human rhinovirus $C$ is a common trigger for bronchiolitis causing paediatric ICU admission. In this study, human rhinovirus C was only slightly less prevalent than RSV. 


\section{Paediatric respiratory epidemiology \\ Asthma}

An association between maternal alcohol ingestion during pregnancy and childhood asthma often proves negative in smaller cohorts [113], but was explored by SHAHEEN et al. [114] in the large Avon Longitudinal Study of Parents and Children (ALSPAC) cohort using a novel approach. A maternal genetic variant (alcohol dehydrogenase $(\mathrm{ADH}) 1 \mathrm{~B}$ ) was used as a surrogate for maternal alcohol intake because mutant gene carriers do not tolerate alcohol well. In their analysis of 6701 mother-child pairs no association was found between the $\mathrm{ADH} 1 \mathrm{~B}$ variant and childhood asthma or eczema. Continuing their research into antenatal exposures, DE MARCO et al. [115] explored the relationship between maternal stressful life events during pregnancy and asthma outcomes in 3854 children aged 3-14 years. The mechanism underlying such a relationship might include maternal cortisol release [116]. A stressful life event, including divorce and bereavement, was reported in $9 \%$ of mothers and was associated with a $50 \%$ increased risk for wheeze and eczema and a $70 \%$ rise in the risk for asthma and rhinitis. On the cusp of antenatal and postnatal exposures, the association between caesarean section delivery and increased asthma risk was explored by EkEUs et al. [117]. An association was found with elective caesarean section, but not emergency caesarean section, and increased asthma. This association might reflect minor immaturity of infants born by elective caesarean section; there is a line of reasoning that infants scheduled for elective caesarean section delivery and at risk for asthma should be born closer to 40 weeks rather than 38 weeks to reduce the risk of asthma. Obesity is a postnatal exposure, and others have described an association between obesity and asthma, but left open the question whether the relationship reflects association or causation. GoKsör et al. [118] reported that, in a Swedish cohort $(\mathrm{n}=5398)$, weight at one and 4.5 years were associated with increased risk for recurrent wheezing at 4.5 years, independent of wheezing in infancy. SMITH et al. [119] addressed the same question in a study using a whole population approach. They provided evidence that obesity and asthma prevalence increased through the 1980s and 1990s, reached a plateau in the early 2000s and fell by 2009. This trend might point to a third factor driving both asthma and obesity.

\section{Primary ciliary dyskinesia}

PCD is a relatively rare condition but one which frequently enters a clinician's differential diagnosis [120]. In a retrospective review of 223 cases, including 28 with confirmed PCD, DJAKOw et al. [121] identified seven questions for use in an algorithm to determine the risk for PCD: perinatal problems, cough in the first 2 months, pneumonia, severe ear infections, chronic rhinorrhoea and recurrent upper respiratory tract infections. Scores varied between $0-7$ and $>75 \%$ of PCD patients and only $6 \%$ of patients without PCD scored $>4$. The investigators, therefore, suggested that for screening a score of $>2$ could reduce the number of referrals by $50 \%$. In a second PCD presentation, in a retrospective series of 220 cases referred to three Belgian centres (Leuven, Ghent and Brussels), Boon et al. [122] found 67 cases with normal ultrastructure of whom 39 also had normal beat frequency; these 39 cases would have been missed without ciliogenesis in culture.

\section{Bronchopulmonary dysplasia}

RoEHR et al. [123] addressed the question whether infants with very low birth weight and BPD have a lower trajectory for lung growth than infants with very low birth weight without BPD. This important, but very difficult, question was addressed using longitudinal lung function assessments in a cohort of 29 infants with and 26 infants without BPD. The take home message was that several indices of unadjusted lung function were worse for infants with BPD but this difference was lost when adjusted for weight, i.e. the lung function reduction was due to reduced weight and not to $\mathrm{BPD}$ per se.

\section{Wheezing bronchitis}

Two common preschool recurrent wheezing phenotypes are recognised, episodic viral wheeze (EVW) and multitrigger wheeze (MTW) [124], but are these truly distinct conditions? Many children with asthma have a history of previous EVW episodes suggesting an intermediate phenotype, in which EVW evolves into MTW. In their study investigating this question, SPYCHER et al. [125] used prospective data from more than 18000 preschool children in the ALSPAC and Leicester cohorts. They observed that, in both cohorts, among those in which preschool wheeze persisted $>2$ years, the wheezing phenotype was maintained in $\sim 50 \%$ of those with EVW and 80\% with MTW. This finding confirms the progression from EVW to MTW, but also describes MTW progressing to EVW. This progressive course might suggest that EVW and MTW are two ends of the same disease process. Evidence underlining the apparent inequity in asthma diagnosis across Europe came from a study by BROZEK et al. [126], which enrolled over 13000 children aged 6-14 years from Poland, Belarus and Ukraine, and in which $75 \%$ of questionnaires were returned. Children in the three countries were matched for age and sex. The prevalence of shortness of breath was highest in children from Belarus, wheeze was highest in the Ukraine, but the diagnosis of asthma was highest in Poland. 


\section{Bronchology}

Chronic tracheostomy in children may be life-saving but is associated with many potential complications. The risk of late postoperative complications, such as tracheal wall granuloma, tracheomalacia or decannulation failure, suggests routine endoscopic evaluation. In a retrospective study conducted in children with long-term tracheostomy who underwent flexible airway endoscopy for routine surveillance and additionally scheduled because of disease or tracheostomy-related complications, PfLEGER et al. [127] reported that the most common findings were airway malacia $(38 \%)$, and clinically relevant granulation tissue in the suprastomal region (8\%), at the end of the cannula (7\%) and in other regions (13\%). Although children with tracheostomies are a heterogeneous population, complications may develop in up to $77 \%$ [128]. The high incidence of airway abnormalities found in this study and the possibility of intervention make flexible bronchoscopy particularly useful. PfLeGer et al. [127] recommend routine evaluation every 6-12 months to assess airway disorders, detect and treat complications (e.g. granulomas), assess tube size and position, and determine readiness for decannulation.

Tracheomalacia is increasingly recognised as an underlying abnormality associated with chronic respiratory illness and is frequently misdiagnosed as asthma or other respiratory conditions. Tracheomalacia as a cause of recurrent lower airways infections may be undertreated, with the risk of additional damage to the lung and airways. Flexible bronchoscopy is used for the diagnostic work-up in patients with clinically suspected tracheomalacia [129]. Nevertheless, the diagnosis in certain cases is complex and uncertain. Scarce information is available on the normal range of central airway collapse among infants and children of various ages and sedation may aggravate airway narrowing. Using imaging in a group of school age patients suspected of having tracheomalacia, KREMMYDAS et al. [130] acquired a dynamic helical CT scan. The ratio of anteroposterior/transverse diameter was measured in the thoracic inlet and at carina level, in full inspiration and at end expiration. Patients also underwent flexible bronchoscopy under deep sedation and spontaneous breathing. Flexible bronchoscopy confirmed tracheomalacia in all the patients and helical CT scans showed localised narrowing of the intrathoracic trachea in nearly half. The authors concluded that CT scans can estimate endothoracic tracheomalacia more accurately than flexible bronchoscopy because they are uninfluenced by general anaesthesia. Future research may propose a complementary or even alternative role for flexible bronchoscopy and CT in diagnosing tracheomalacia. Recent publications describe multidetector CT imaging protocols specifically designed for infants and children in daily clinical practice [131].

Endoscopic therapeutic interventions now provide beneficial results in paediatric patients with diverse airway diseases. Endobronchial laser therapy can be used for several, mostly iatrogenic, airway problems, such as subglottic stenosis in intubated patients or suprastomal granulomas in patients with tracheostomy. In a study underlining its benefits, ANTÓN-PACHECO et al. [132] presented outcomes after laser therapy in a large series of selected patients with congenital and acquired airway lesions, including laryngomalacia (29\%), granulation tissue $(21 \%)$, vocal cord paralysis $(19 \%)$, laryngeal stenosis $(13 \%)$ and vascularlymphatic malformation (8\%). In $89 \%$ of patients, laser therapy achieved partial or complete clinical improvement. Complications arose in two patients, one with post-laser bleeding and aspiration, and the other with subcutaneous emphysema and pneumothorax. Endoscopic laser therapy, therefore, appears to be a safe and effective technique for various airway disorders in children.

Another new development involves measuring airway carbon content in children with airway problems. Carbon content in sputum macrophages has been used as a marker for individual exposure to biomass smoke. Carbonaceous particulate matter may also affect lung function in children [133, 134]. In a study including flexible bronchoscopy, SNIJDERS et al. [135] reported on black carbon, the major component of inhalable particulate matter, in airway macrophages sampled by bronchoalveolar lavage from children with chronic lower airway diseases, such as recurrent lower airways infections and asthma. The median area of black carbon correlated with air PM10 (particulate matter with an aerodynamic diameter up to $10 \mu \mathrm{m}$ ) levels during the week before the children underwent bronchoscopy. This observation indicates that airway macrophage carbon content reflects short-term exposure to particulate matter, although the effect may be manifested both directly [136] and cumulatively [137].

\section{References}

Eber E, Aurora P, Lødrup Carlsen KC, et al. Paediatrics in Amsterdam. Eur Respir J 2012; 40: 215-226. Albloushi A, Simpson S, Stick S, et al. Feasibility and safety of mannitol challenge in pre-school children using forced oscillations. Eur Respir J 2012; 40: Suppl. 56, 150s.

3 Ioan I, Varechova S, Bonabel C, et al. Reversibility of airway obstruction to diagnose asthma in children using forced oscillations: Inspiration, expiration does it matter? Eur Respir J 2012; 40: Suppl. 56, 589s.

4 Radics B, Gyurkovits Z, Szabó H, et al. Within-breath changes in respiratory impedance in healthy neonates. Eur Respir J 2012; 40: Suppl. 56, 195s.

5 Franken H, Clément J, Cauberghs M, et al. Oscillating flow of a viscous compressible fluid through a rigid tube: a theoretical model. IEEE Trans Biomed Eng 1981; 28: 416-420. 
Hantos Z, Radics B, Gyurkovits Z, et al. Oscillations mechanics of the respiratory system in healthy newborns. Am J Respir Crit Care Med 2012; 185: A6149.

7 Ratjen F, Salazar J, Gibney K, et al. Validation of multiple breath washout technology in healthy children and children with CF. Eur Respir J 2012; 40: Suppl. 56, 841s.

8 Fuchs S, Petri E, Hülskamp G, et al. Routine measurement of the LCI in CF with an ultrasonic device for multiple breath nitrogen washout. Eur Respir J 2012; 40: Suppl. 56, 841s.

9 Fuchs SI, Sturz J, Junge S, et al. A novel sidestream ultrasonic flow sensor for multiple breath washout in children. Pediatr Pulmonol 2008; 43: 731-738.

10 Hatziagorou E, Avramidou V, Kirvassilis F, et al. Sensitivity of lung clearance index and chest computed tomography in early lung disease among children with non-CF bronchiectasis. Eur Respir J 2012; 40: Suppl. 56, 842 s.

11 Hatziagorou E, Avramidou V, Kirvassilis F, et al. Lung clearance index and exercise capacity among children with bronchiectasis. Eur Respir J 2012; 40: Suppl. 56, 842s.

12 Green K, Buchvald F, Madsen A, et al. Ventilation inhomogeneity in children with cystic fibrosis and primary ciliary dyskinesia. Eur Respir J 2012; 40: Suppl. 56, 589s.

13 Stanojevic S, Wade A, Stocks J. Reference values for lung function: past, present and future. Eur Respir J 2010; 36: $12-19$.

14 Stocks J, Stanojevic S, Cole T, et al. All-age multi-ethnic reference values for spirometry: The global lung function initiative (GLI). Eur Respir J 2012; 40: Suppl. 56, 572s.

15 Quanjer PH, Stanojevic S, Cole TJ, et al. Multi-ethnic reference values for spirometry for the 3-95-yr age range: the global lung function 2012 equations. Eur Respir J 2012; 40: 1324-1343.

16 Ulrich S, Hildenbrand F, Treder U, et al. Reference values for the 6-minute walk test in healthy children. Eur Respir J 2012; 40: Suppl. 56, 168s-169s.

17 ATS Committee on Proficiency Standards for Clinical Pulmonary Function Laboratories. ATS statement: guidelines for the six-minute walk test. Am J Respir Crit Care Med 2002; 166: 111-117.

18 Filippone M, Bonetto G, Cherubin E, et al. Childhood course of lung function in survivors of bronchopulmonary dysplasia. JAMA 2009; 302: 1418-1420.

19 Oruc M, Gunlemez A, Uyan ZS, et al. The evaluation of lung function measured by impulse oscillometry method in very low birth weight born children at preschool age. Eur Respir J 2012; 40: Suppl. 56, 767s.

20 Zivanovic S, Paris MA, Lunt A, et al. Lung function and gender at twelve to thirteen years of age in children born very prematurely. Eur Respir J 2012; 40: Suppl. 56, 843s.

21 Wong J, Belik J, Humpl T, et al. Sleep disordered breathing in children with trisomy 21 and pulmonary hypertension. Eur Respir J 2012; 40: Suppl. 56, 250 s.

22 LoMauro A, Romei M, D’Angelo G, et al. Inefficient cough in Duchenne muscular dystrophy (DMD). Eur Respir J 2012; 40: Suppl. 56, 249s.

23 Hedlin G, Bush A, Lødrup Carlsen K, et al. Problematic severe asthma in children, not one problem but many: a GA²LEN initiative. Eur Respir J 2010; 36: 196-201.

24 Lødrup Carlsen KC, Hedlin G, Bush A, et al. Assessment of problematic severe asthma in children. Eur Respir J 2011; 37: 432-440.

25 Bush A, Pedersen S, Hedlin G, et al. Pharmacological treatment of severe, therapy-resistant asthma in children: what can we learn from where? Eur Respir J 2011; 38: 947-958.

26 de Benedictis FM, Carloni I, Bush A. The dark side of the moon: severe therapy-resistant asthma in children. Monaldi Arch Chest Dis 2012; 77: 83-93.

27 Tillie-Leblond I, Deschildre A, Gosset P, et al. Difficult childhood asthma: management and future. Clin Chest Med 2012; 33: 485-503.

28 Kupczyk M, Wenzel S. U.S. and European severe asthma cohorts: what can they teach us about severe asthma? J Intern Med 2012; 272: 121-132.

29 Jarjour NN, Erzurum SC, Bleecker ER, et al. Severe asthma: lessons learned from the National Heart, Lung, and Blood Institute Severe Asthma Research Program. Am J Respir Crit Care Med 2012; 185: 356-362.

30 Ullmann N, Adams A, Bossley CJ, et al. IL-33 and airway remodelling in paediatric severe therapy resistant asthma. Eur Respir J 2012; 40: Suppl. 56, 860s.

31 Heida F, Pijnenburg M, Vanlaeken L, et al. Bronchoscopy and endobronchial biopsies in children: Useful or not? Eur Respir J 2012; 40: Suppl. 56, 860s.

32 Konradsen J, Nordlund B, Pedroletti C, et al. Exhaled nitric oxide in children with severe asthma. Eur Respir J 2012; 40: Suppl. 56, 860s.

33 Bossley CJ, Fleming L, Gupta A, et al. Pediatric severe asthma is characterized by eosinophilia and remodeling without TH2 cytokines. J Allergy Clin Immunol 2012; 129: 974-982.

34 Ibrahim M, Nwokoro C, Sanak M, et al. Urinary eicosanoids and preschool wheeze phenotype. Eur Respir J 2012; 40: Suppl. 56, 860s-861s.

35 Prescott S, Nowak-Wegrzyn A. Strategies to prevent or reduce allergic disease. Ann Nutr Metab 2011; 59: Suppl. 1, 28-42.

36 Abrahamsson TR, Jakobsson HE, Andersson AF, et al. Low diversity of the gut microbiota in infants with atopic eczema. J Allergy Clin Immunol 2012; 129: 434-440.

37 Strickland DH, Judd S, Thomas JA, et al. Boosting airway T-regulatory cells by gastrointestinal stimulation as a strategy for asthma control. Mucosal Immunol 2011; 4: 43-52.

38 Chauveau A, Dalphin ML, Kaulek V, et al. Changes in skin prick test (SPT) from the age of 1 to 6 years (yrs) and relationship to specific IgE and atopic dermatitis: The French arm of PASTURE European study. Eur Respir J 2012; 40: Suppl. 56, 861s.

39 Michel S, Busato F, Genuneit J, et al. DNA methylation in asthma and allergy related genes is influenced by farm exposure and time trends in early childhood. Eur Respir J 2012; 40: Suppl. 56, 861s.

40 Dogaru CM, Strippoli MP, Spycher BD, et al. Breastfeeding and lung function at school age: does maternal asthma modify the effect? Am J Respir Crit Care Med 2012; 185: 874-880.

41 Nathan P, Dehmel S, Imker R, et al. Maternal genetic asthma predisposition affects signaling networks in lungs of neonatal offspring. Eur Respir J 2012; 40: Suppl. 56, 337s. 

sex of the child. J Allergy Clin Immunol 2012; 130: 427-434

43 Zhang L, Prietsch S, Mendes AP, et al. Inhaled corticosteroids and risk of oropharyngeal colonization by streptococcus pneumoniae in children with asthma. Eur Respir J 2012; 40: Suppl. 56, 585s-586s.

44 Korona-Glowniak I, Niedzielski A, Malm A. Upper respiratory colonization by Streptococcus pneumoniae in healthy pre-school children in south-east Poland. Int J Pediatr Otorhinolaryngol 2011; 75: 1529-1534.

45 Beck JM, Young VB, Huffnagle GB. The microbiome of the lung. Transl Res 2012; 160: $258-266$

46 Sze MA, Dimitriu PA, Hayashi S, et al. The lung tissue microbiome in chronic obstructive pulmonary disease. Am J Respir Crit Care Med 2012; 185: 1073-1080.

47 Brinkmann F, Schwerk N, Kabech M, et al. Wheeze in preschool age is associated with pulmonary bacterial infection and resolves after antibiotic therapy. Eur Respir J 2012; 40: Suppl. 56, 759s.

48 Holt PG, Sly PD. Interaction between adaptive and innate immune pathways in the pathogenesis of atopic asthma: operation of a lung/bone marrow axis. Chest 2011; 139: 1165-1171.

49 Good JT Jr, Rollins DR, Martin RJ. Macrolides in the treatment of asthma. Curr Opin Pulm Med 2012; 18: 76-84.

50 Caramori G, Papadopoulos N, Contoli M, et al. Asthma: a chronic infectious disease? Clin Chest Med 2012; 33: 473-484.

51 Sidoroff V, Hyvärinen M, Kröger L, et al. Inhaled corticosteroids and bone mineral density in children: a prospective 12-year follow-up study after early-life wheezing. Eur Respir J 2012; 40: Suppl. 56, 585s.

52 Zoellner E, Lombard CJ, Galal U, et al. Hypothalamic-pituitary-adrenal axis suppression in children at Cape Town allergy units - prevalence and predictive factors. Eur Respir J 2012; 40: Suppl. 56, 759s.

53 Koo S, Gupta A, Fainardi V, et al. Ethnic variation in response to intramuscular triamcinolone in children with severe therapy resistant asthma. Eur Respir J 2012; 40: Suppl. 56, 585s.

54 Sheikh S, Khan N, Frasure M, et al. Role of $\mathrm{MgSO}_{4}$ in PICU management of children with status asthmaticus. Eur Respir J 2012; 40: Suppl. 56, 760s.

55 Ater D, Shai H, Bar BE, et al. Hypertonic saline and acute wheezing in pre-school children. Eur Respir J 2012; 40: Suppl. 56, 586s.

56 Mays L, Ammon-Treiber S, Mothes B, et al. Modified mRNA encoding Foxp3 protects against allergic asthma in mice by rebalancing T helper cell responses through an IL-23/IL-17A-dependent mechanism. Eur Respir J 2012; 40: Suppl. 56, $586 \mathrm{~s}$.

57 Barben J, Rueegg CS, Gallati S, et al. Comparison of nanoduct versus macroduct sweat test for the diagnosis of cystic fibrosis in the newborn screening programme in Switzerland. Eur Respir J 2012; 40: Suppl. 56, 608s.

58 Sly PD, Brennan S, Gangell C, et al. Lung disease at diagnosis in infants with cystic fibrosis detected by newborn screening. Am J Respir Crit Care Med 2009; 180: 146-152.

59 Regamey N, Jeffery PK, Alton EW, et al. Airway remodelling and its relationship to inflammation in cystic fibrosis. Thorax 2011; 66: 624-629.

60 Poreddy S, Shackleton C, Kappers J, et al. Respiratory infections in young children with cystic fibrosis: a community-based longitudinal study. Eur Respir J 2012; 40: Suppl. 56, 299s.

61 Poreddy S, Withers A, Cox D, et al. Prevalence of tracheobronchomalacia in young children with cystic fibrosis. Eur Respir J 2012; 40: Suppl. 56, 607s.

62 Mete S, Gokdemir Y, Peker S, et al. Oral health and some risk factors in children with cystic fibrosis. Eur Respir J 2012; 40: Suppl. 56, 607s-608s.

63 Welsh L, King L, Robinson P. Lung function decline in a modern cystic fibrosis cohort. Eur Respir J 2012; 40 : Suppl. 56,605 s.

64 Godding V, Stevens L, Lebecque P, et al. Active and passive smoking by CF patients in Belgium: a national survey. Eur Respir J 2012; 40: Suppl. 56, 608s.

65 Tepper L, Utens E, Caudri D, et al. Tracking disease progression in cystic fibrosis using bronchiectasis, trapped air and quality of life. Eur Respir J 2012; 40: Suppl. 56, 261s.

66 Cebrian M, Ferrero J, Ansotegui E, et al. Comparative study of three quality of life instruments in adolescents and adults with cystic fibrosis. Eur Respir J 2012; 40: Suppl. 56, 605s.

67 Hofer M, Hirt A, Kurowski T, et al. Comparison of the Cystic Fibrosis Questionnaire with the St George's Respiratory Questionnaire in adult patients with cystic fibrosis. Eur Respir J 2012; 40: Suppl. 56, 605s.

68 Avdeev S, Baimakanova G, Krasovsky S, et al. Home non-invasive ventilation (HNIV) improves survival in hypercapnic patients with cystic fibrosis. Eur Respir J 2012; 40: Suppl. 56, 294s.

69 Gustafsson PM, De Jong PA, Tiddens HA, et al. Multiple-breath inert gas washout and spirometry versus structural lung disease in cystic fibrosis. Thorax 2008; 63: 129-134.

70 Belessis Y, Dixon B, Hawkins G, et al. Early cystic fibrosis lung disease detected by bronchoalveolar lavage and lung clearance index. Am J Respir Crit Care Med 2012; 185: 862-873.

71 Robinson PD, Latzin P, Verbanck S, et al. Guidelines for inert gas washout measurement using multiple- and single-breath tests. Eur Respir J 2013; 41: 507-522.

72 Yammine S, Singer F, Latzin P. One size does not fit all - impact of the one liter tidal volume breathing protocol on indices from nitrogen multiple-breath washout in children. Eur Respir J 2012; 40: Suppl. 56, 259s.

73 Lum S, Stocks J, Stanojevic S, et al. Age and height dependence of lung clearance index and functional residual capacity. Eur Respir J 2013; 41: 1371-1377.

74 Houltz B, Green K, Lindblad A, et al. Tidal $\mathrm{N}_{2}$ washout ventilation inhomogeneity indices in a reference population aged 7-70 years. Eur Respir J 2012; 40: Suppl. 56, 694s.

75 Singer F, Houltz B, Robinson P, et al. Bench test of a mass spectrometer based multiple-breath washout system using a realistic lung model. Eur Respir J 2012; 40: Suppl. 56, 841s.

76 AL-Khathlan N, Gaillard E, Beardsmore C. Lung clearance index (LCI) and hyperinflation in children with cystic fibrosis (CF). Eur Respir J 2012; 40: Suppl. 56, 261s.

77 Verbanck S, Paiva M, Paeps E, et al. Lung clearance index in adult CF patients: the role of convection-dependent lung units. Eur Respir J 2013; 42: 380-388.

78 Amin R, Subbarao P, Jabar A, et al. Hypertonic saline improves the LCI in paediatric patients with CF with normal lung function. Thorax 2010; 65: 379-383. 
79 Ratjen F, Salazar J, Jensen R, et al. Alternative multiple breath washout outcomes for clinical trials in cystic fibrosis. Eur Respir J 2012; 40: Suppl. 56, 317s.

$80 \mathrm{Al}$ Jassim F, Lindblad A, Gustafsson P. Peripheral airway function and severity of CF lung disease - a cross-sectional study from childhood to late middle age. Eur Respir J 2012; 40: Suppl. 56, 262 s.

81 Singer F, Kieninger E, Abbas C, et al. Practicability of nitrogen multiple-breath washout measurements in a pediatric cystic fibrosis outpatient setting. Pediatr Pulmonol 2013; 48: 739-746.

82 Zirbes J, Prais D, Dunn C, et al. Assessment of lung function in pre-school children with cystic fibrosis by nitrogen washout. Eur Respir J 2012; 40: Suppl. 56, 317s.

83 Yammine S, Singer F, Abbas C, et al. Ways to shorten the lung clearance index mesurement I - are three measurements needed? Eur Respir J 2012; 40: Suppl. 56, 841s.

84 Singer F, Yammine S, Abbas C, et al. Ways to shorten the lung clearence index measurement II - how long to wash? Eur Respir J 2012; 40: Suppl. 56, 590s.

85 Abbas C, Singer F, Casaulta C, et al. Short term effects of chest physiotherapy in children with cystic fibrosis assessed by a new lung function test. Eur Respir J 2012; 40: Suppl. 56, 262 s.

86 Ramsey BW, Davies J, McElvaney NG, et al. A CFTR potentiator in patients with cystic fibrosis and the G551D mutation. N Engl J Med 2011; 365: 1663-1672.

87 Elborn JS, Wainwright C, Sermet-Gaudelus I, et al. Effects of the CFTR potentiator, ivacaftor, in two phase 3 trials in subjects with CF who have the G551D-CFTR mutation. Eur Respir J 2012; 40: Suppl. 56, 316 s.

88 Ratjen F, Sheridan H, Lee PS, et al. Effect of ivacaftor on lung clearance index and FEV1 in subjects with CF who have the G551D-CFTR mutation and mild lung disease. Eur Respir J 2012; 40: Suppl. 56, 316s.

89 McKone E, Rodriguez S, Yen K, et al. Long-term safety and efficacy of ivacaftor in subjects with CF who have the G551D-CFTR mutation. Eur Respir J 2012; 40: Suppl. 56, 316 s.

90 Lim SS, Vos T, Flaxman AD, et al. A comparative risk assessment of burden of disease and injury attributable to 67 risk factors and risk factor clusters in 21 regions, 1990-2010: a systematic analysis for the Global Burden of Disease Study 2010. Lancet 2012; 380: 2224-2260.

91 Suri R, Mushtaq N, Waite R, et al. Additive effect of air pollution particulate matter and cigarette smoke on pneumococcal adhesion to lower airway cells. Eur Respir J 2012; 40: Suppl. 56, 761s.

92 Kim HH, Chun YH, Yoon JS, et al. Sodium sulfite enhances rhinovirus-induced chemokine production in airway epithelial cells. Eur Respir J 2012; 40: Suppl. 56, 761s.

93 Spencer D, Thomas M, Mohammed E, et al. National surveillance of paediatric empyema in the UK; the UK-ESPE study. Eur Respir J 2012; 40: Suppl. 56, 540s.

94 Cox D, Khoo SK, Ferrari G, et al. Evidence of increased pathogenicity of HRVC compared with HRVA and B: comparisons between children with an acute lower respiratory illness and controls. Eur Respir J 2012; 40: Suppl. 56, $541 \mathrm{~s}$.

95 Wilson $\mathrm{K}$, Bingle L, Bingle $\mathrm{C}$, et al. Differential responses of monolayer and differentiated airway epithelial cell cultures to NTHi infection. Eur Respir J 2012; 40: Suppl. 56, 762s.

96 Ghorbani P, Santhakumar P, Palaniyar N, et al. Effect of short-chain fatty acids and pH on aerobic and anaerobic growth of Pseudomonas aeruginosa. Eur Respir J 2012; 40: Suppl. 56, 542s.

97 Walker W, Jackson C, Lackie L, et al. Is primary ciliary dyskinesia a "biofilm" disease? Eur Respir J 2012; 40: Suppl. 56, 540s.

98 Walker W, Jackson C, Harris A, et al. Longitudinal microbiology of children with primary ciliary dyskinesia. Eur Respir J 2012; 40: Suppl. 56, 543s.

99 Smyth RL, Openshaw PJ. Bronchiolitis. Lancet 2006; 368: 312-322.

100 Mitchell I, Paes B, Li A, et al. RSV hospitalization in Down syndrome in the Canadian Registry of Synagis (CARESS) following prophylaxis (2006-2011). Eur Respir J 2012; 40: Suppl. 56, 541s.

101 Skjerven HO, Hunderi JOG, Brügmann-Pieper K, et al. Inhaled racemic adrenalin versus saline in acute bronchiolitis, a multicenter randomized double-blind clinical trial. Eur Respir J 2012; 40: Suppl. 56, 540s.

102 Turner SW, Young S, Goldblatt J, et al. Childhood asthma and increased airway responsiveness: a relationship that begins in infancy. Am J Respir Crit Care Med 2009; 179: 98-104.

103 Schaap L, Flokstra-de Blok BMJ, van der Hulst J, et al. Development of a quality of life instrument for children with bronchopulmonary dysplasia. Eur Respir J 2012; 40: Suppl. 56, 764s.

104 Daraki A, Zachaki S, Polycarpou E, et al. The association of NQO1 C609T polymorphism and the susceptibility of bronchopulmonary dysplasia in preterm neonates. Eur Respir J 2012; 40: Suppl. 56, 764s.

105 Hokuto I, Arimitsu T, Matsuzaki Y, et al. G-CSF administration improves chronic lung disease caused by exposure to high-concentration oxygen in neonatal mice. Eur Respir J 2012; 40: Suppl. 56, 765s.

106 Rojas-Reyes MX, Morley CJ, Soll R. Prophylactic versus selective use of surfactant in preventing morbidity and mortality in preterm infants. Cochrane Database Syst Rev 2012; 3: CD000510.

107 Finer NN, Carlo WA, Walsh MC, et al. Early CPAP versus surfactant in extremely preterm infants. N Engl J Med 2010; 362: 1970-1979.

108 Dunn MS, Kaempf J, de Klerk A, et al. Randomized trial comparing 3 approaches to the initial respiratory management of preterm neonates. Pediatrics 2011; 128: e1069-e1076.

109 Hull J, Aniapravan R, Chan E, et al. British Thoracic Society guideline for respiratory management of children with neuromuscular weakness. Thorax 2012; 67: Suppl. 1, i1-i40.

110 Robertson MJP, Morley SL, Ross Russell RI. Short-term use of noninvasive ventilation in the paediatric population. ERS Buyers Guide 2011; 68-76.

111 Hufton M, Millen G, Kallappa C, et al. Use of high flow nasal oxygen (HFNO) for bronchiolitis in a general paediatric ward: preliminary experiences. Eur Respir J 2012; 40: Suppl. 56, 766s.

112 Cox D, Siew-Kim K, Guicheng Z, et al. HRVC is the commonest rhinovirus group detected in children admitted to a paediatric intensive care unit with respiratory illnesses. Eur Respir J 2012; 40: Suppl. 56, 766 s.

113 Yuan W, Sørensen HT, Basso O, et al. Prenatal maternal alcohol consumption and hospitalization with asthma in childhood: a population-based follow-up study. Alcohol Clin Exp Res 2004; 28: 765-768.

114 Shaheen S, Rutterford C, Zuccolo L, et al. Prenatal alcohol exposure and childhood atopic disease: a Mendelian randomisation approach. Eur Respir J 2012; 40: Suppl. 56, 516s-517s. 
115 de Marco R, Pesce G, Girardi P, et al. Foetal exposure to maternal stressful events increases the risk of having asthma and atopic diseases in childhood. Eur Respir J 2012; 40: Suppl. 56, 517s.

116 Wright RJ. Stress and atopic disorders. J Allergy Clin Immunol 2005; 116: 1301-1306.

117 Ekeus C, Bråbäck L, Lowe A, et al. Elective caesarean section affects the risk of asthma medication in children up to five years of age. Eur Respir J 2012; 40: Suppl. 56, 852s.

118 Goksör E, Alm B, Pettersson R, et al. Increased risk of preschool wheeze both with higher BMI in infancy and at age 4 years. Eur Respir J 2012; 40: Suppl. 56, 518s.

119 Smith S, Aucott L, Tagiyeva N, et al. Secular trends in childhood obesity, asthma, eczema and hayfever over 45 years. Eur Respir J 2012; 40: Suppl. 56, 852s.

120 Barbato A, Frischer T, Kuehni CE, et al. Primary ciliary dyskinesia: a consensus statement on diagnostic and treatment approaches in children. Eur Respir J 2009; 34: 1264-1276.

121 Djakow J, Rozehnalova E, Havlisova M, et al. Clinical index to evaluate the risk of primary ciliary dyskinesia in children. Eur Respir J 2012; 40: Suppl. 56, 517s.

122 Boon M, Smits A, Jorissen M, et al. PCD with normal ultrastructure is not rare. Eur Respir J 2012; 40: Suppl. 56, 517s.

123 Roehr C, Wilitzki S, Proquitté $\mathrm{H}$, et al. Development of postnatal lung function in very low birth weight infants with or without BPD. Eur Respir J 2012; 40: Suppl. 56, 517s.

124 Brand PL, Baraldi E, Bisgaard H, et al. Definition, assessment and treatment of wheezing disorders in preschool children: an evidence-based approach. Eur Respir J 2008; 32: 1096-1110.

125 Spycher BD, Sterne JAC, Granell R, et al. Multiple trigger and episodic viral wheeze in early childhood: are these phenotypes stable over time? Eur Respir J 2012; 40: Suppl. 56, 517s-518s.

126 Brozek G, Zejda J, Fedortsiv O, et al. Belarus Ukraine Poland Asthma Study (BUPAS) - prevalence of asthma, respiratory symptoms and allergic diseases in children. Eur Respir J 2012; 40: Suppl. 56, 855s.

127 Pfleger A, Eber E. Bronchoscopic findings and interventions in patients with long-term tracheostomy. Eur Respir J 2012; 40: Suppl. 56, 598s.

128 Carr MM, Poje CP, Kingston L, et al. Complications in pediatric tracheostomies. Laryngoscope 2001; 111: 1925-1928.

129 Boogaard R, Huijsmans SH, Pijnenburg MW, et al. Tracheomalacia and bronchomalacia in children: incidence and patient characteristics. Chest 2005; 128: 3391-3397.

130 Kremmydas G, Grammeniatis V, Douros K, et al. Computed tomography and flexible bronchoscopy techniques for assessment of tracheomalacia in children. Eur Respir J 2012; 40: Suppl. 56, 598s.

131 Lee EY, Boiselle PM. Tracheobronchomalacia in infants and children: multidetector CT evaluation. Radiology 2009; 252: 7-22.

132 Antón-Pacheco JL, Luna C, García-Hernández G, et al. Endoscopic laser-assisted management of pediatric airway lesions: a single institution experience. Eur Respir J 2012; 40: Suppl. 56, 600s.

133 Kulkarni N, Pierse N, Rushton L, et al. Carbon in airway macrophages and lung function in children. N Engl J Med 2006; 355: 21-30

134 Kulkarni NS, Prudon B, Panditi SL, et al. Carbon loading of alveolar macrophages in adults and children exposed to biomass smoke particles. Sci Total Environ 2005; 345: 23-30.

135 Snijders D, Bottecchia L, Storer V, et al. Carbon in the airway macrophages of children affected by chronic lower airway disease. Eur Respir J 2012; 40: Suppl. 56, 599s.

136 Nastos PT, Paliatsos AG, Anthracopoulos MB, et al. Outdoor particulate matter and childhood asthma admissions in Athens, Greece: a time-series study. Environ Health 2010; 9: 45.

137 Gauderman WJ, Avol E, Gilliland F, et al. The effect of air pollution on lung development from 10 to 18 years of age. $N$ Engl J Med 2004; 351: 1057-1067. 